\title{
Randomised, placebo controlled trial of nebulised furosemide for breathlessness in patients with cancer
}

\author{
A Wilcock, ${ }^{1}$ A Walton, ${ }^{1}$ C Manderson, ${ }^{1}$ L Feathers, ${ }^{1}$ B El Khoury, ${ }^{1}$ M Lewis, \\ A Chauhan, ${ }^{1}$ P Howard, ${ }^{1}$ S Bell, ${ }^{1}$ J Frisby, ${ }^{1}$ A Tattersfield ${ }^{2}$
}

${ }^{1}$ Department of Palliative Medicine, Nottingham University Hospitals NHS Trust, City Hospital Campus, Nottingham, UK; ${ }^{2}$ Department of Respiratory Medicine, Nottingham University Hospitals NHS Trust, City Hospital Campus, Nottingham, UK

Correspondence to:

Dr A Wilcock, Hayward House

Specialist Palliative Cancer Care

Unit, Nottingham University

Hospitals NHS Trust, City

Hospital Campus, Nottingham

NG5 1PB, UK:

andrew.wilcock@

nottingham.ac.uk

Received 3 October 2007 Accepted 21 March 2008 Published Online First

11 April 2008

\section{ABSTRACT}

Background: Breathlessness is a common and difficult symptom to treat in patients with cancer. Case reports suggest that nebulised furosemide can relieve breathlessness in such patients but few data are available.

Method: Patients with primary or secondary lung cancer and a Dyspnoea Exertion Scale score of $\geqslant 3$ were recruited. Following familiarisation, patients received either nebulised furosemide $40 \mathrm{mg}$ or nebulised $0.9 \%$ saline under double blind conditions or no treatment, in random order on 3 consecutive days. Patients undertook number reading and arm exercise tests to assess breathlessness and its impact, and were asked to report subjective benefit and any preference between nebulised treatments

Results: 15 patients took part. There were no differences between furosemide, saline and no treatment in the outcomes of the number reading test (eg, mean number read per breath was 6.7, 6.4 and 6.7, respectively) or arm exercise test (eg, mean Borg score at maximum equivalent workload was 2.3, 2.5 and 2.7, respectively). No adverse effects were reported, although there was a small fall in forced expiratory volume in $1 \mathrm{~s}$ and forced vital capacity following saline. Six patients considered that their breathlessness improved with nebulised treatment, three preferring saline, one furosemide and two reporting they were of equal benefit.

Conclusions: Our findings do not support a beneficial effect from nebulised furosemide in patients with cancer related breathlessness.

Listed on the National Research Register (N0170118249) and the UK Clinical Research Network Portfolio Database (1428).

Breathlessness is common in patients with incurable lung cancer. About half of such patients say that breathlessness interferes with physical activities and a quarter report that it affects mood, enjoyment of life and relationships with others. ${ }^{1}$ A systematic review supports the use of opioids to relieve breathlessness but the benefit is fairly small and adverse effects can occur. ${ }^{2}$ New approaches are required.

In healthy volunteers, nebulised furosemide 20-40 mg has improved air hunger and respiratory discomfort induced by hypercapnia during constrained ventilation ${ }^{3}$ or in combination with an inspiratory resistive load. ${ }^{4}$ Nebulised furosemide $40 \mathrm{mg}$ also reduced breathlessness during endurance but not incremental exercise testing in patients with chronic obstructive pulmonary disease $^{5}$ and there are reports of benefit from nebulised furosemide $20 \mathrm{mg}$ in a small number of patients with cancer. ${ }^{6-8}$ However, the only reported controlled study, a randomised double blind, crossover pilot study in seven patients with cancer, found no difference in the difficulty or distress of breathing assessed by visual analogue scale between nebulised furosemide $20 \mathrm{mg}$ and $0.9 \%$ saline. Five of the seven patients said their breathing deteriorated following furosemide. ${ }^{9}$

The objective of the current randomised, double blind, placebo controlled, crossover study was to examine the benefit of nebulised furosemide on breathlessness in patients with cancer, assessed by the number reading and arm exercise tests. A no treatment day was included as a second control to help assess the magnitude of any placebo or adverse effects resulting from nebulised saline.

\section{METHODS}

\section{Subjects}

Patients with primary or secondary lung cancer or mesothelioma with breathlessness on low levels of exertion or at rest (ie, a score of $\geqslant 3$ on the Dyspnoea Exertion $\mathrm{Scal}^{10}$ ) were recruited from oncology or respiratory clinics, a respiratory ward and a specialist palliative care unit. All were experiencing breathlessness that had developed or increased since cancer had been diagnosed. Patients with chronic obstructive pulmonary disease (COPD) were eligible as long as they had stable disease and their breathlessness was deemed to be predominantly cancer related. Patients were excluded if breathlessness could be relieved by treatment such as drainage of a pleural effusion or blood transfusion. Other reasons for exclusion included radiotherapy or chemotherapy within 4 weeks, asthma, angina, heart failure or any problem that might affect the patient's ability to read aloud or undertake arm exercise. The dose of any drug that could potentially affect exercise or breathlessness had to have been stable for at least 4 days prior to the study. Patients gave written informed consent and the study was approved by Nottingham City Hospital research ethics committee, and by the National Cancer Research Network as a locally adopted study.

\section{Measurements}

\section{Dyspnoea Exertion Scale}

The Dyspnoea Exertion Scale, a modified version of the Medical Research Council Dyspnoea Scale, was used to select and categorise patients..$^{10}$ It ranges 
from $0=$ "I am able to walk at my own pace on the level without getting breathless over any distance" to $5=$ "I am breathless at rest".

\section{Spirometric values}

Forced expiratory volume in $1 \mathrm{~s}\left(\mathrm{FEV}_{1}\right)$ and forced vital capacity (FVC) were measured with the patients seated as the best of three recordings using a dry wedge spirometer (Vitalograph Type R Spirometer, Buckingham, UK) or hand held spirometer (Micro Spirometer, Micro Medical, Rochester, Kent, UK), depending on whether the patient was studied in the palliative care unit or a hospital side room. Patients used the same device on each day.

\section{Number reading test}

This has been developed to measure the limiting effect of breathlessness on reading numbers aloud at rest. ${ }^{11}$ While seated, patients are given a page containing a grid of numbers and asked to read the numbers aloud and in order as quickly and clearly as they can. The number of breaths taken and the number of numbers read over $60 \mathrm{~s}$ is recorded. The procedure is repeated five times using the same grid of numbers. Patients are allowed to recover between readings and continue when they feel rested. The highest number obtained from the five readings and the number of numbers read per breath during this reading are noted.

\section{Arm exercise test}

This has been developed to assess breathlessness in patients with cancer who are breathless at low levels of exertion. ${ }^{12}$ While seated, patients are asked to move an outstretched arm between two points $20 \mathrm{~cm}$ above and $20 \mathrm{~cm}$ below shoulder height in time to a regular audible beat ( 80 beats $/ \mathrm{min}$ ) with no verbal

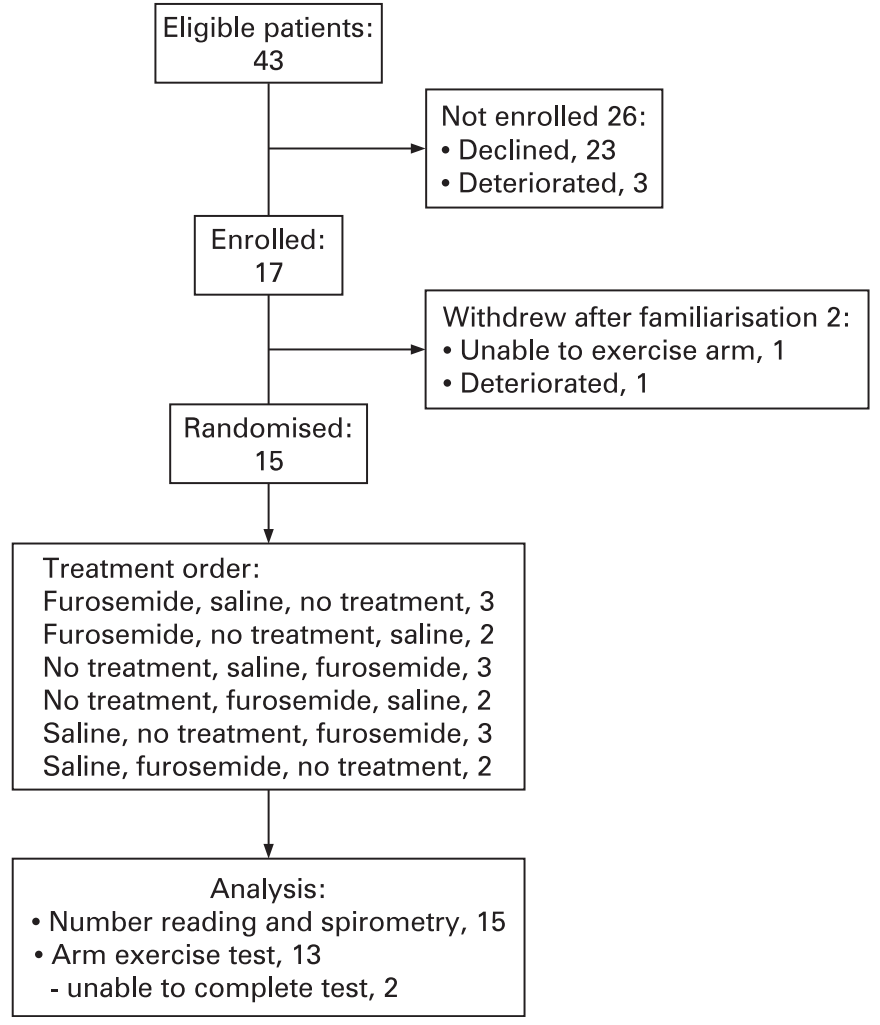

Figure 1 Study flow diagram. encouragement. At 1 min intervals, patients are asked to quantify their sensation of breathlessness by pointing to a modified Borg scale ${ }^{13}$ and then switch to exercising the other arm. The Borg scale is a vertical scale labelled from 0 to 10 with corresponding expressions of increasing sensation intensity from "nothing at all" to "maximal". Breathlessness was defined to the patients as "a feeling of an uncomfortable need to breathe rather than other sensations associated with exercise, such as fatigue or the awareness that ventilation had simply increased". Patients are asked to continue the exercise for as long as possible. Breathlessness scores at the maximum duration of exercise attained by each patient in all three tests were used in the analysis.

\section{Protocol}

Tests were carried out in a quiet room in the palliative care unit or a ward side room. Patients were given written instructions to avoid caffeine for $1 \mathrm{~h}$, large meals for $2 \mathrm{~h}$ and excess alcohol from the night before the tests. Medication and times of drug administration were unchanged during the study, which ran over 4 days. The initial day was for familiarisation with the equipment, surroundings and procedure. On the next 3 days, at the same time of day, patients undertook the assessments following nebulised furosemide $40 \mathrm{mg}$ or $0.9 \%$ saline under double blind conditions, or no treatment. An independent pharmacist prepared the nebulised treatments following a treatment order generated using randomised permuted blocks containing the six possible orders of treatment. Furosemide and saline (both $4 \mathrm{ml}$ ) were given by jet nebuliser (HOT Top Plus, Intersurgical, Wokingham, UK; particle mass median diameter $3.25 \mu \mathrm{m}$ ) attached to a facemask and driven with air at $81 / \mathrm{min}$. The nebuliser was attached to a facemask and patients were instructed to take slow deep breaths through their mouth until $1 \mathrm{~min}$ after the nebuliser started to splutter (approximately $5 \mathrm{~min}$ ). Spirometry was measured immediately before and after the nebulised treatment ended. After $10 \mathrm{~min}$ of rest, patients underwent the number reading test and, after a further $10 \mathrm{~min}$ rest, the arm exercise test. On the no treatment day, patients underwent spirometry followed by the number reading and arm exercise tests, as above. Patients emptied their bladder immediately before each study and urine output was measured over the next $2 \mathrm{~h}$. The patient was allowed one $125 \mathrm{ml}$ drink during this period. At the end of the study patients were asked if they had perceived any benefit from the nebulised treatment and, if so, any difference between the two treatments.

The primary outcome was the two end points of the number reading test-namely, the total number read and the number read per breath. Our previous within subject, between day data indicated that nine and 15 patients, respectively, would be required to detect a change in these two end points $(90 \%$ power; $p=0.05$ ) equivalent to $50 \%$ of that seen following drainage of a pleural effusion. ${ }^{11}$ We had hoped to recruit 30 patients but, because of slow accrual, recruitment was discontinued after reaching the minimum number.

\section{Statistical analysis}

Repeated measures analysis of variance was used to test for carry over, period and for treatment effects to establish the within subject difference in the mean values of number of numbers read, number of numbers read per breath, the modified Borg score at maximum equivalent work load, duration of arm exercise and urine output between the three treatment groups. Change in spirometric values following nebulised furosemide 
Table 1 Number reading and arm exercise test outcomes, spirometric values and urine output following nebulised furosemide or nebulised saline and on a no treatment study day

\begin{tabular}{|c|c|c|c|c|}
\hline & Furosemide & Saline & No treatment & p Value \\
\hline \multicolumn{5}{|l|}{ Number reading test $(n=15)$} \\
\hline \multicolumn{5}{|l|}{ No of numbers read } \\
\hline Total & $68(16)$ & $70(15)$ & $70(16)$ & 0.91 \\
\hline Per breath & $6.7(7.9)$ & $6.4(5.1)$ & $6.7(5.9)$ & 0.64 \\
\hline \multicolumn{5}{|l|}{ Arm exercise test $(n=13)$} \\
\hline Duration of arm exercise (s) & 452 (349) & $485(345)$ & $467(342)$ & 0.96 \\
\hline Borg score at maximum equivalent work load & $2.3(1.5)$ & $2.5(1.4)$ & $2.7(1.9)$ & 0.83 \\
\hline \multicolumn{5}{|l|}{ Change in spirometric values $(n=15)$} \\
\hline $\mathrm{FEV}_{1}(\mathrm{ml})$ & $-10(80)$ & $-80(90)$ & - & 0.03 \\
\hline FVC (ml) & $10(100)$ & $-70(80)$ & - & 0.02 \\
\hline Urine output $(m l)(n=10)$ & $202(124)$ & $203(131)$ & $199(150)$ & 0.99 \\
\hline
\end{tabular}

Values are mean (SD). $\mathrm{FEV}_{1}$, forced expiratory volume in $1 \mathrm{~s}$; $\mathrm{FVC}$, forced vital capacity.

and saline were compared by paired $t$ test. Calculations were performed using the Statistical Package for the Social Sciences (SPSS) V.14.0. A $p$ value of $<0.05$ was regarded as statistically significant.

\section{RESULTS}

Recruitment commenced in October 2002 and was stopped when 15 patients (eight females; mean (SD) age 66 (11) years) had completed the study (fig 1). Their median (range) Eastern Co-operative Oncology Group performance status was 2 (1-3). All had thoracic cancer, either primary (non-small cell lung $(n=7)$, mesothelioma $(n=2)$ ), or secondary (breast $(n=2)$, one each from the pancreas, thymus, uterus and unknown). Regular medication included opioids $(n=13)$, benzodiazepines $(n=4)$ and oxygen $(n=3)$. Seven patients were receiving bronchodilators although only one had a documented diagnosis of COPD. Mean (SD) $\mathrm{FEV}_{1} / \mathrm{FVC}$ ratio was 75 (11)\%. The Dyspnoea Exertion Scale categorised three, eight and four patients as experiencing breathlessness moving around in bed or getting out of bed (level 3), on talking (level 4) or at rest (level $5)$, respectively. To date, 13 patients have died with a median (range) survival of 51 (5-353) days.

All patients were able to complete all the number reading tests satisfactorily. Two patients were unable to complete the arm exercise tests, despite a satisfactory familiarisation test, and could not be included in this analysis.

No carryover or period effect was found for the number of numbers read per minute ( $p=0.2$ and $p=0.09$, respectively) or per breath ( $p=0.55$ and $p=0.73$, respectively). Across the 3 study days, patients read a mean (range) of 70 (43-103) numbers per minute, and 6.1 (2.3-35) numbers per breath. There were, however, no significant differences between the number of numbers read per minute $(68,70,70 ; p=0.91)$ or per breath $(6.7,6.4,6.7 ; p=0.64)$ between the three treatments (tables 1, 2).

All 13 patients who completed the arm exercise test experienced an increase in breathlessness during exercise apart from one who scored breathlessness as "very slight" throughout. Across the 3 study days, the mean duration of arm exercise was $457 \mathrm{~s}$ (7.62 min), representing a mean of 609 arm movements. There were, however, no significant differences between the duration of arm exercise $(452,485,467 \mathrm{~s} ; \mathrm{p}=0.96)$ or Borg score at maximum equivalent workload $(2.3,2.5,2.7 ; \mathrm{p}=0.83)$ between the three treatments (tables 1,2).

Following nebulised saline, there was a fall in $\mathrm{FEV}_{1}$ and FVC of $8 \%$ and $5 \%$ from baseline, respectively. After nebulised furosemide, the changes in $\mathrm{FEV}_{1}$ and $\mathrm{FVC}$ were $1 \%$ or less. The differences between the two treatments $(70 \mathrm{ml}$ and $80 \mathrm{ml})$ were statistically significant (tables 1,2). No difference was found in urine output in the 10 patients with a reliable urine collection (tables 1, 2). No adverse effects were reported by patients following nebulised furosemide or saline.

Six of the 15 patients considered that their breathlessness improved with nebulised treatment, with three preferring saline, one furosemide and two finding the nebulised treatments of equal benefit.

Table 2 Between treatment differences (95\% confidence intervals) for the number reading and arm exercise test outcomes, spirometric values and urine output

\begin{tabular}{|c|c|c|c|}
\hline & $\begin{array}{l}\text { Furosemide } \\
\text { vs no treatment }\end{array}$ & $\begin{array}{l}\text { Saline } \\
\text { vs no treatment }\end{array}$ & $\begin{array}{l}\text { Furosemide } \\
\text { vs saline }\end{array}$ \\
\hline \multicolumn{4}{|l|}{ Number reading test $(n=15)$} \\
\hline \multicolumn{4}{|l|}{ No of numbers read } \\
\hline Total & $1.1(-1.4,3.7)$ & $-1.3(-4.9,2.2)$ & $2.4(-1.6,6.5)$ \\
\hline Per breath & $0.1(-0.9,1.1)$ & $0.5(-0.4,1.4)$ & $-0.5(-1.2,0.3)$ \\
\hline \multicolumn{4}{|l|}{ Arm exercise test $(n=13)$} \\
\hline Duration of arm exercise (s) & $27(-19,71)$ & $13(-54,26)$ & $40(-17,98)$ \\
\hline Borg score at maximum equivalent work load & $0.4(-0.2,1)$ & $0.2(-0.3,0.8)$ & $0.2(-0.2,0.6)$ \\
\hline \multicolumn{4}{|l|}{ Change in spirometric values $(n=15)$} \\
\hline $\mathrm{FEV}_{1}(\mathrm{ml})$ & - & - & $-68(-122,-15)$ \\
\hline $\mathrm{FVC}(\mathrm{ml})$ & - & - & $-87(-153,-20)$ \\
\hline Urine output ( $\mathrm{ml} ; \mathrm{n}=10)$ & $-4(-92,84)$ & $-5(-83,72)$ & $-2(-100,97)$ \\
\hline
\end{tabular}

$\mathrm{FEV}_{1}$, forced expiratory volume in $1 \mathrm{~s}$; FVC, forced vital capacity. 


\section{DISCUSSION}

In this randomised controlled study in 15 patients with cancer related breathlessness, we found no evidence of benefit from nebulised furosemide $40 \mathrm{mg}$ on any outcome measure. Only one of six patients who considered their breathlessness to have improved with nebulised treatment chose nebulised furosemide over $0.9 \%$ saline. Our findings do not support a beneficial effect of nebulised furosemide in this patient group.

Breathlessness is a distressing symptom for many patients with thoracic cancer and few treatments are available. Despite this, there is a paucity of research into finding new treatments. Undertaking formal trials in these patients is challenging and recruitment is difficult. Assessing breathlessness is also difficult, particularly when it is experienced at such low levels of exertion as to make most forms of exercise testing impractical. The number reading test and the arm exercise test were developed to help assess breathlessness in patients with cancer who are breathless on minimum exertion. The former is a measure of the limiting effect of breathlessness on reading numbers aloud at rest and the latter allows breathlessness to be measured in patients who become breathless on low level exertion. We have shown that both are acceptable to patients and repeatable. ${ }^{11} 12$ The number reading test was used as the primary outcome measure and our sample size was sufficient to detect a change equivalent to $50 \%$ of that seen following a thoracocentesis (mean volume $1840 \mathrm{ml}$ ). ${ }^{11}$

The negative findings in our study differ from some previous reports in patients with breathlessness related to cancer. Sixteen of the 19 patients described in three reports benefited from nebulised furosemide $20 \mathrm{mg}$ administered as a single dose (13 patients) ${ }^{6} 8$ or $20 \mathrm{mg}$ four times a day for up to 3 weeks (three patients). ${ }^{7}$ However, the only controlled study of nebulised furosemide in seven patients with cancer related breathlessness showed no benefit, in keeping with our findings. ${ }^{9}$ The benefit seen in the case reports may therefore be a placebo effect. Differences in the underlying lung pathology causing cancer related breathlessness is another possible explanation, although this varied considerably in the case reports as it did in our patients. Nebulised furosemide has also reduced experimentally induced breathlessness in healthy subjects ${ }^{3}{ }^{4}$ but the relevance of this to patients with cancer is uncertain.

In our study, there was a small fall in $\mathrm{FEV}_{1}$ and FVC after nebulised saline of $80 \mathrm{ml}$ and $70 \mathrm{ml}$, respectively. Bronchoconstriction following nebulised $0.9 \%$ saline has been seen in patients with asthma and COPD, and attributed to a non-specific bronchoconstrictor response to airway cooling. ${ }^{14} 15$ The fact that the change was less following nebulised furosemide is in keeping with the ability of furosemide to protect against such non-specific bronchoconstrictor stimuli. ${ }^{16}$

Our finding contrasts with the small increase in $\mathrm{FEV}_{1}(50 \mathrm{ml})$ seen following nebulised furosemide $40 \mathrm{mg}$ in 20 patients with COPD undergoing an incremental exercise test. ${ }^{5}$ However, bronchodilatation in this study may have been caused by the exercise $^{17}$ rather than nebulised furosemide, as the authors suggest. Although nebulised furosemide is very effective in inhibiting bronchoconstriction due to antigen and non-specific stimuli in patients with asthma, ${ }^{16}$ it has not caused bronchodilatation in these studies.

Although larger doses or more frequent administration of nebulised furosemide may have been more effective, the dose we gave was larger than the $20 \mathrm{mg}$ dose associated with benefit in 12 of the 15 patients reported by Kohara et al, ${ }^{6}$ and similar doses are sufficient to inhibit bronchoconstriction in patients with asthma. ${ }^{18}$ We also considered whether our outcome measures were insufficiently sensitive to detect a beneficial effect, but the lack of patient preference for nebulised furosemide suggests we did not miss a clinically important difference.

Thus our findings do not support a beneficial effect from a single dose of $40 \mathrm{mg}$ of nebulised furosemide in patients with cancer related breathlessness.

Acknowledgements: We would like to thank the patients and staff who took part or supported this study, Sarah Lewis, Andrea Venn and Matthew Maddocks, for statistical support, and Robert Twycross for his helpful comments.

Funding: This study was made possible by support from the Hayward House Cancer Care Trust.

Competing interests: None.

Ethics approval: The study was approved by Nottingham City Hospital research ethics committee, and by the National Cancer Research Network as a locally adopted study.

\section{REFERENCES}

1. Tanaka K, Akechi T, Okuyama T, et al. Prevalence and screening of dyspnoea interfering with daily life activities in ambulatory patients with advanced lung cancer J Pain Symptom Manage 2002;23:484-9.

2. Jennings A, Davies AN, Higgins JPT, et al. A systematic review of the use of opioids in the management of dyspnoea. Thorax 2002;57:939-44

3. Moosavi SH, Binks AP, Lansing RW, et al. Effect of inhaled furosemide on air hunger induced in healthy humans. Respir Physiol Neurobiol 2006;156:1-8.

4. Nishino T, Ide T, Sudo T, et al. Inhaled furosemide greatly alleviates the sensation of experimentally induced dyspnea. Am J Respir Crit Care Med 2000;161:1963-7.

5. Ong KC, Kor A, Chong W, et al. Effects of inhaled furosemide on exertional dyspnea in chronic obstructive pulmonary disease. Am J Respir Crit Care Med 2004;169:1028-33.

6. Kohara $\mathbf{H}$, Ueoka $H$, Aoe $K$, et al. Effect of nebulized furosemide in terminally ill cancer patients with dyspnea. J Pain Symptom Manage 2003;26:962-7.

7. Shimoyama N, Shimoyama M. Nebulized furosemide as a novel treatment for dyspnea in terminal cancer patients. J Pain Symptom Manage 2002;23:73-6.

8. Stone P, Kurowska A, Tookman A. Nebulised frusemide for dyspnoea. Palliat Med 1994;8:258.

9. Stone $\mathbf{P}$, Rix E, Kurowska A, et al. Re: nebulized furosemide for dyspnea in terminal cancer patients. J Pain Symptom Manage 2002;24:274-5.

10. Heyse-Moore LH. On dyspnea in advanced cancer. MD thesis. Southampton: University of Southampton, 1993.

11. Wilcock A, Crosby V, Clarke D, et al. Reading numbers aloud: a measure of the limiting effect of breathlessness in patients with cancer. Thorax 1999:54:1099-103.

12. Wilcock A, Walker G, Manderson C, et al. Use of upper limb exercise to assess breathlessness in patients with cancer: Tolerability, repeatability and sensitivity. J Pain Symptom Manage 2005;29:559-64

13. Burdon JGW, Juniper EF, Killian KJ, et al. The perception of breathlessness in asthma. Am Rev Respir Dis 1982;126:825-8.

14. Lewis RA, Lewis MN, Tattersfield AE. Asthma induced by suggestion: is it due to airway cooling? Am Rev Respir Dis 1984;129:691-5.

15. Taube C, Holz O, Mücke M, et al. Airway response to inhaled hypertonic saline in patients with moderate to severe chronic obstructive pulmonary disease. Am J Respir Crit Care Med 2001;164:1810-15.

16. Cavaliere F, Masieri S. Furosemide protective effect against airway obstruction. Curr Drug Targets 2002;3:197-201.

17. Natif N, Shiner RJ, Gaides M, et al. Improved breathing capacity during exercise in severe obstructive airway disease. Respir Physiol 1998;112:145-54.

18. Bianco S, Pieroni MG, Refini RM, et al. Protective effect of inhaled furosemide on allergen-induced early and late asthmatic reactions. N Engl J Med 1989;321:1069-73. 